\title{
IJITIHAD SULTAN MUHAMMAD IDRUS KAIMUDDIN IBNU BADARUDDIN AL BUTHUNI (1824-1851): Akulturasi Islam dengan Budaya di Kesultanan Buton
}

\author{
Basrin Melamba dan Wa Ode Siti Hafsah \\ Universitas Haluoleo Kendari \\ Jalan M.T Haryono, Anduonou, Kendari, Sulawesi Tenggara 93132 \\ email: melambabasrin@yahoo.com
}

\begin{abstract}
The coming of Islam in the Buton Sultanate has brought a change in the social, political, even in the intellectual aspects. It produced scholars with the thought or ijitihad as a blend of Islamic and local cultures. One of the scholars as well as Buton Sultan was Muhammad Idrus Kaimuddin Ibnu Badaruddin Al Buthuni (1824-1851). His thought or ijitihad found the essence of the concept of manners according to the teachings of the ancestors in kabanti Bula Malino. His several works became the guidance of the public and court authorities in the Sultanate of Buton which were basically rooted from the teachings of Islam. Kaimuddin's thought in terms of ethics, morals, manners, or advice showed his horizons of knowledge and the depth of leadership thought. The magnitude of Islamic influence in some of his works proves the enduring process of Islamic acculturation done continuously and deeply since the era of Buton Islamic empire. Kaimuddin's thought is essentially a formation process of Buton's civilization centered on the palace and passed to Buton society in general through the process of cultural dialogue between Buton culture (Wolio) and Islam.

Masuknya agama Islam di Kesultanan Buton, telah membawa perubahan dalam bidang sosial, politik, bahkan dalam aspek intelektual. Hal ini melahirkan ulama-ulama yang memiliki pemikiran atau ijitihad yang merupakan perpaduan
\end{abstract}


budaya Islam dan budaya lokal. Salah satu ulama di Buton sekaligus sebagai Sultan yaitu Muhammad Idrus Kaimuddin Ibnu Badaruddin Al Buthuni (18241851). Pemikiran atau ijitihad Sultan Kaimuddin menemukan esensi konsep tata krama menurut ajaran leluhur dalam kabanti Bula Malino. Beberapa karyanya menjadi tuntunan masyarakat dan penguasa kraton di Kesultanan Buton yang banyak bersumber dari ajaran Islam. Pemikiran dalam hal etika, moral, tata krama, maupun nasehat Sultan Kaimuddin menunjukkan cakrawala pengetahuan dan mendalamnya pemikiran seorang pemimpin. Besarnya pengaruh Islam dalam beberapa karya Sultan Kaimuddin membuktikan berlangsungnya proses akulturasi Islam secara berkesinambungan dan mendalam dari masa kerajaan Islam Buton. Hasil pemikiran Sultan Kaimuddin pada hakekatnya merupakan sebuah proses pembentukan peradaban Buton yang berpusat pada kraton dan ditularkan pada masyarakat Buton secara umum melalui dialog kebudayaan antara kebudayaan Buton (Wolio) dengan Islam.

Keywords: thoughts, Islam and local culture

\section{Pendahuluan}

Dewasa ini budi pekerti generasi penerus bangsa sebagian sudah terpengaruh oleh hal-hal yang sifatnya negatif sehingga mengarah pada penyimpangan perilaku dan budi pekerti yang kurang baik. Hal-hal yang negatif semakin hari semakin marak. Kejahatan tumbuh marak di mana-mana, tanpa terkecuali kejahatan di kampus. Kejadian perampokan, perkelahian, tawuran, penyalahgunaan narkoba, korupsi, pembunuhan secara keji dan biadab tak asing lagi di negeri ini. Hal itu dapat disaksikan setiap hari baik secara langsung maupun secara tidak langsung melalui berita di media masa. Kejadian-kejadian seperti itu sudah sangat memprihatinkan.

Selain itu, di kalangan mahasiswa sebagian telah lepas dari tatakrama dan sopan santun; sopan dalam berperilaku, santun dalam berbahasa. Dalam pergaulan, mereka itu tidak lagi mengenal kakak, adik, orang tua, guru, dosen sudah enggan menyapa atau memberi salam kepada sesama yang lebih tua. Mereka tak punya beban untuk berkata yang jorok, kotor dan kasar. Mengumpat dan memaki orang yang terpandang atau orang terhormat sekalipun, mereka merasa tak berdosa, merasa biasa-biasa saja. Sungguh bagi yang masih bersih hatinya, jiwanya yang belum tekontaminasi dengan hal-hal yang tidak berkenan seperti itu patut prihatin.

Permasalahan bangsa di era globalisasi dan modernisasi makin pelik, salah satunya sikap dan moral bangsa yang semakin terpuruk, korupsi, perkelahian pelajar, tawuran mahasiswa, kurang sopan, tindakan asusila bersina, minum 
khamar, pembohongan publik, adu domba, konflik Sara, dan sebagainya. Untuk mencegah hal tersebut maka pada setiap kesempatan pertemuan forum resmi baik itu di forum seminar, simposium, dialog, sarasehan, dan sebagainya, pada setiap kesempatan pertemuan digagas pentingnya dilaksanakan pendidikan budi pekerti dan etika, atau pendidikan karakter bagi bangsa. Apakah bangsa ini sebelumnya memang memiliki karakter yang edan, tidak beretika, tidak sopan, tidak beradab, dan berbagai stigma negatif?, Jawabannya tidak. Jika ditelisik kembali zaman, khususnya kehidupan manusia Indonesia masa lalu, mereka telah mewariskan pendidikan karakter, moral, etika, pekerti, maupun kearifan hidup yang diajarkan baik melalui lisan maupun tersirat.

Salah satu contoh kearifan pendidikan etika, moral, dan karakter berupa pemikiran pada masa lalu telah ada zaman kerajaan tradisional di Indonesia salah satunya di Kesultanan Buton di Sulawesi Tenggara. Pada masa Sultan Muhammad Idrus Kaimuddin beliau melahirkan suatu pemikiran atau ijitihad mengenai kemulian sosok pribadi bagi masyarakat Buton baik di lingkungan kraton maupun diluar lingkungan masyarakat kraton.

Dalam tulisan ini mengangkat pokok kajian tentang masalah ijitihad atau pemikiran etika kehidupan yang tersirat dalam nasihat Sultan Muhammad Idrus dalam kabanti maupun beberapa karya beliau sebagai salah satu unsur kebudayaan orang Buton yang hidup dilingkungan masyarakat Kraton pada abad ke-19. Ajaran etika kehidupan yang menjadi tuntunan masyarakat Buton tersebut digali dari kabanti Bula Malino karangan Sultan Muhammad Idrus Kaimuddin maupun beberapa karyanya, beliau merupakan salah seorang pujangga kraton Buton sekaligus sebagai Sultan yang terkenal yaitu Sultan Muhammad Idrus Kaimuddin.

Ajaran-ajaran moral yang mencerahkan bagi masyarakatnya yang sedang mengalami situasi krisis moral, sebagai akibat dari krisis di kraton. Pada hakekatnya Sultan Muhammad Idrus Kaimuddin berfungsi sebagai guru masyarakat pada zamannya. Menemukan esensi konsep tata krama atau etika menurut ajaran pemikiran Sultan Muhammad Idrus Kaimuddin yang menjadi tuntunan masyarakat kraton Kesultanan Buton yang pada dasarnya banyak bersumber dari ajaran agama Islam.

Bahwa kelahiran pemikiran berupa ajaran-ajaran moral, etika, agama dan kehidupan masyarakat kraton Buton yang berlangsung melalui akulturasi antara Islam dan kebudayaan Buton pada hakekatnya merupakan sebuah proses pembentukan peradaban Buton yang berpusat pada kraton dan ditularkan pada masyarakat Buton secara umum, yang melalui melalui proses 
dialog kebudayaan antara kebudayaan Buton dengan kebudayaan Islam. Diakui telah terjadi akulturasi antara kebudayaan Buton dengan Islam atau sebaliknya menurut Haliadi bahwa telah terjadi pembauran antara budaya Islam dan budaya atau adat Buton (Haliadi, 2006: 25). Meskipun demikian pembahasan mengenai ijitihad seorang Sultan Muhammad Idrus Kaimuddin belum menjadi pokok kajiannya.

Kajian mengenai historiografi Islam di Indonesia sudah banyak dilakukan, terutama di daerah Jawa. Sedangkan studi sejarah Islam di luar Jawa masih minim apalagi di daerah Sulawesi, khususnya di daerah Sulawesi Tenggara. Sejarah sebagai salah satu cabang Ilmu Sosial perlu mendapatkan perhatian serius dari Ulama dan santri, serta umat Islam Indonesia. Banyak karya sejarah Islam Indonesia dan dunia Islam yang beredar di sekitar. Namun, banyak pula isinya sangat bertentangan dengan apa yang diperjuangkan oleh Rasulullah SAW. Apalagi dengan adanya deislamisasi sejarah Indonesia, peranan ulama dan santri, serta umat Islam di dalamnya ditiadakan. Atau tetap ada, tetapi dimaknai dengan pengertian lain. Seruan perlunya memerhatikan sejarah sebagai tulisan dijelaskan dalam al Quran "Wal tandhur nafsun ma qaddamat li qhad" artinya perhatikan sejarahmu untuk esokmu, (QS. al Hasyr, 59: 18).

\section{Riwayat Hidup Sultan Muhammad Idrus Kaimuddin}

Muhammad Idrus Kaimuddin memiliki nama lengkap yaitu Muhammad Idrus Kaimuddin Ibnu Badaruddin al Buthuni. Beliau adalah ulama sufi ternama dari kesultanan Buton di Sulawesi Tenggara. Muhammad Idrus Kaimuddin lahir pada akhir abad ke-18, ia memangku jabatan Sultan pada tahun 1824, pada usia sekitar 40 tahun. Pada masa mudanya, ia menerima pendidikan Islam dari kakeknya. Sultan La Jampi, yang juga pernah menjadi Sultan dengan gelar Sultan Qa'im al Din Tua (1763-1788). Sampai pada tahun 1874, orang Buton masih menemukan jejak tempat ia dibina oleh kakeknya dalam pengetahuan agama, khususnya tasawuf, lembaga pendidikan itu terkenal dengan pesantren Zawiyyah. Ia berguru pada Syekh Muhammad bin Syais Sumbul al Makki. Dari ulama inilah ia menerima tarikat khalwatiyah sammaniyah. Tulisan-tulisannya yang khusus membahas tentang tasawuf.

Sultan Muhammad Idrus Kaimuddin naik tahta mengantikan ayahnya Sultan Muhammad Anharuddin yang usia kekuasaannya sangat pendek (1822-1823) (Zahari, 1977: III, 28). Malah ada kesan bahwa sebenarnya Sultan Anharuddin (Sultan Buton ke-28) seperti Sultan Carateker, sebab pada tahun 1821 Sultan Kaimuddin I, penganti Sultan Anharuddin, sudah mengadakan 
hubungan resmi lewat surat penguasa sipil dan militer Belanda di Makassar (Suryadi, 2006: 8). Tercatat bahwa Sultan Kaimuddin I baru naik tahta 1824. Menurut Mulku Zahri, nama biasa Sultan Kaimuddin I adalah Muhammad Idrus nama lainnya: Aedurusu Matambe, Mokobiadina, Oputa I Kuba, Oputa Mancuana; gelar kesultanan: Sultan Kaimuddin I; masa jabatan 1824-1851; meninggalkan kedudukannya karena mangkat; tempat pemakaman: Badia, dekat masjid Sultan; aliran bangsawan: Kumbewaha yang ke-8 (Zahari, 1977: III, 28). Gelar Sultan Kaimuddin I dalam stempelnya adalah: al Sultan kaimuddin ibn Abdullah. Allahumma Malik al mulk tu' ti almulk daa im bi dawan.

Sultan Kaimuddin I yang memiliki latar belakang pendidikan agama yang kuat telah melakukan beberapa perubahan dalam system ketatanegaraan dan administrasi pemerintahan Kerajaan Buton, menetapkan beberapa undang-undang baru yang mengatur hak dan kewajiban kaum ningrat dan masyarakat. Baginda juga mewajibkan penggunaan Bahasa Arab sebagai bahasa pengantar dalam lingkungan kraton Wolio (Zahari, 1977: 28-29). Sultan juga banyak menulis buku untuk menambah pengetahuan masyarakatnya. Baginda juga menjalin hubungan regional yang lebih baik dengan kerajaan-kerajaan tetangganya.

Sultan Muhammad Idrus Kaimudin, seorang pujangga Wolio Abad Ke-19. Pada masa kesultanan Muhammad Idrus, dikenal beberapa pujangga Wolio yang tidak dapat dilupakan jasa-jasanya dalam upaya pendidikan dan pengembangan Islam melalui karya tulis. Melalui tulisan mereka mengembangkan ilmu-ilmu pengetahuan tentang Islam. Mereka tuangkan dalam bentuk syair, sehingga mudah diterima dan dicernah oleh pembacanya. Karena itu dengan cepat pula rakyat dapat memahami apa yang diajarkan. Dalam karya, mereka memakai bahasa Wolio, Arab Jawi (Melayu Kuno) dan bahasa Arab. Bukubuku yang berbahasa Arab dan Arab Jawi berisi pendidikan syareat Islam sedangkan Kabanti mengenai sejarah kebudayaan serta jalur jalan mengenal hidup dunia dan kehidupan di alam kekal abdi, mengantarkan faham dan pengertian sufi, membawa pembacanya kepada ilmu tentang kesufian.

Muhammad Idrus disamping sebagai Sultan (Kepala Pemerintahan), juga menghasilkan karya tulisnya tercatat tidak kurang dari 40 judul diantaranya seperti: Raudlatul Ikhwan (Bahasa Arab); Takhsiynul Auladi (Bahasa Arab); Darratil Ikhkaami (Bahasa Arab); Sabiylis Salaam (Bahasa Arab); Targiybul Anaami (Bahasa Arab); Dliaaul Anwaari (Bahasa Arab); Tanbiygil Gaafili (Bahasa Wolio-Kabanti); Jaohara Maanikamu Molabi (Bahasa Wolio-Kabanti); Nuru Molabina (Bahasa Arab-kabanti); Tankiyyatul Kuulubi (Bahasa Arab); Bula 
Malino (Bahasa Wolio-Kabanti); Siraajul Muttaqina (Bahasa Arab); Badayatul Alamiyyat (Bahasa Arab);

Buku-buku yang disebutkan di atas sangat digemari di Wolio terutama yang mengenai buku syair Kabanti. Ditiap rumah pada memiliki buku Kabanti sekurang-kurangnya salinan dari satu judul atau dua. Kabanti itu dibaca dengan dilagukan dengan nada yang khas. Sejak anak-anak mengenal baca Arab Wolio, mereka telah diberi kesempatan oleh orang tua untuk mempelajarinya. Tentu terbatas menurut tingkat isi buku yang dibacanya, sebab ada pula yang tidak bisa dibaca oleh anak-anak.

\section{Tata Krama dalam Ajaran Sultan Muhammad Idrus Kaimuddin}

1. Tata Krama terhadap Diri Sendiri

Manusia dituntut senantiasa berbuat baik atau beretika baik terhadap dirinya sendiri, orang lain maupun kepada Tuhan-Nya. Oleh karena itu manusia berkewajiban menyembah Tuhan dengan dengan panduan al Quran dan Sunnah. Dapat dipahami bahwa etika berkaitan dengan masalah, nilai, aturan, moral, kesusilaan atau perbuatan baik dan buruk.

Nilai etika berhubungan dengan manusia sebagai individu karena menyangkut kehidupan pribadi. Pendukung norma etika adalah nurani individu dan bukan manusia sebagai makhluk sosial atau sebagai anggota masyarakat yang terorganisir. Norma etik ditujukan agar terbentuk kebaikan atau perilaku guna menyempurnakan manusia dan melarang berbuat jahat, seperti, membunuh, berzina, mencuri, menganiaya, merampok, memfitnah dan lain-lain. Sumber norma etika adalah dari manusia sendiri yang bersifat otonom dan tidak ditujukan kepada sikap lahir, tetapi ditujukan kepada sikap batin manusia. Batinnya sendirilah yang mengancam perbuatan yang melanggar norma kesusilaan dengan sanksi tidak ada kekuasaan, di luar dirinya yang memaksakan sanksi itu kalau terjadi pelanggaran norma etika, misalnya pencurian atau penipuan, maka akan timbullah dalam hati nurani si pelanggar timbullah rasa penyesalan, rasa malu, takut dan manusia bersalah.

Konsep Islam mengenai tata krama terhadap diri sendiri merupakan cerminan dari akhlak atau budi pekerti, orang pilihan, indah akhlaknya. Sebagaimana nabi bersabda, "sesungguhnya orang-orang pilihan di antara kamu, adalah yang paling indah budi pekertinya" (HR Muslim). Konsep Islam bahwa kehormatan manusia tergantung pada kebaikan akhlaknya. Manusia senantiasa menyadari akan dirinya mengenai masalah ini. Mengawali nasihatnya, Sultan Muhammad Idrus mengatakan bahwa kelak ia akan menghadapi kematian. 
Hal ini sudah merupakan takdir Tuhan kepadanya sebagai hamba-Nya.Tidak ada satupun hamba Tuhan yang hidup kekal di dunia ini.Yang hidup kekal abadi hanyalah Tuhan semata. Oleh karena itulah, dikala kematiannya tiba, ia memohon kepada Tuhan agar senantiasa diberi kekuatan iman serta dapat mengikrarkan dua kalimat syahadat dengan teguh. Hal ini sebagai mana disuratkan di bawah ini:

\section{Bahasa Walio}

Bismillahi kasi karoku si

Alhamdu padaka kumatemo

Kajanji inamo yoputa momangkana

Yapekamate ßari-ßariya ßatuya

Yinda samia ßatuya ßomolagina

Sakubumbuya pada posamatemo

Somo yopu yalagi saman gongeya

Sakiyayiya yinda kokapada

Ee wayopu dawuyakuiymani

Wakutuna kußoli baDaku si

Te sahada ikiraru momatangka

Tetasidiki iymani mototapu

\section{Terjemahan}

Dengan mama Tuhan, kasihan diriku ini

Segala puji, kelak akan mati

Sudah takdir Tuhan yang kuasa

Mematikan semua hamba

Tidak satu jua hamba yang kekal abadi

Semua akan mati

Hanya Tuhan yang kekal abadi

Selama-lamanya tidak berkesudahan

Wahai Tuhan, berikanlah aku iman

Pada waktu meninggalkan jasad ini

Dengan syahadat ikrar yang teguh

Dan dengan tasdiq iman yang tetap

Sumber: (Laniampe, 2012: 15)

Sultan Muhammad Idrus Kaimuddin memohon pula kepada Allah SWT agar yang ditambahkan rahmat. Ia mengakui bahwa Nabi Muhammad lah yang menjadi sumber cahaya awal yang paling mulia yang memberikan sinar terang kepada hamba Tuhan yang berdosa. Ia juga mengharapkan agar Tuhan dapat mempertemukannya dengan Nabi Muhammad di padang masyhar tempat berkumpulnya hamba. Selain itu ia meminta agar Tuhan dapat mengampuninya dari azab neraka pada hari kemudian. Hal ini sebagaimana disuratkan di bawah ini:

\section{Bahasa Wolio}

Ee wayopu, menganiaya rahamat Muhammadi caheya ßa-ßana

Yoyinciyamo kayinawa motopene Mosuluwina umati mokoDosana

\section{Terjemahan}

Wahai Tuhan, tambahkanlah rahmat

Muhammad cahaya permulaan

Dialah cahaya paling mulia

Yang menyinari hamba yang berdosa 
Syio-siyomo wayopu ßeku pokawa Yi muhusara toromuyana ßatuya Yoga yakuyi azabu naraka Te huru -hara nayile muri-murina
Semoga Tuhan mempertemukanku

Di padang masyhar tempat berkumpulnya hamba Hindarkanlah aku dari azab neraka

Dan keributan pada hari kemudian

Sumber: (Laniampe, 2012; 15)

Nasihat Sultan Muhammad Idrus kepada dirinya disampaikan melalui salah satu syairnya yang diberi judul "Bula Malino Kapekarunana Yinca" yang berarti "Bulan Terang Penyegar Hati”. Sultan Muhammad Idrus mengharapkan, nasehat-nasehat itu dapat menjadi cermin hidupnya dalam mengikuti berbagai pengajaran dan memerangi hatinya yang jelek, serta dapat diterima oleh Tuhan. Hal ini disuratkan di bawah ini:

\section{Bahasa Wolio}

Sisangu nazamu yoni wolio Yikarangina Ayedurusu Matambe Kokarongiya ßetao payiyasaku Bara salana ßekuyose kadari Siyo-siyomo yopu yatarimaku Beku yewangi yimBaku momadakina Kusarongiya Kaßanti yinciya si Bula Malino Kapekarunana Yinca

\author{
Terjemahan \\ Yang satu ini syair berbahasa wolio \\ Di karang Idrus yang hina \\ Kukarang untuk cerminku \\ Semoga aku mengikuti ajaran \\ Mudah-mudahan Tuhan menerimaku \\ Untuk memerangi hatiku yang jelek \\ Kuberi nama syair ini \\ Bulan Terang Penyegar Hati
}

a. Nasihat Sultan kepada dirinya.

Manusia adalah makhluk ciptaan yang paling sempurna dan sebaik-baik ciptaan. Oleh karena itu manusia harus menjaga dirinya dari hal-hal yang merusak kesempurnaan ciptaannya. Manusia dituntut senantiasa berbuat baik atau beretika baik terhadap dirinya sendiri, orang lain maupun kepada Tuhan-Nya. Oleh karena itu manusia berkewajiban menyembah Tuhan dengan dengan panduan al Quran dan Sunnah. Dapat dipahami bahwa etika berkaitan dengan masalah, nilai, aturan, moral, kesusilaan atau perbuatan baik dan buruk. Nilai etik berhubungan dengan manusia sebagai individu karena menyangkut kehidupan pribadi. Pendukung norma etika adalah nurani individu dan bukan manusia sebagai makhluk sosial atau sebagai anggota masyarakat yang terorganisir. 
Norma etik ditujukan agar terbentuk kebaikan atau perilaku guna menyempurnakan manusia dan melarang berbuat jahat, seperti, membunuh, berzina, mencuri, menganiaya, merampok, memfitnah dan lain-lain. Sumber norma etika adalah dari manusia sendiri yang bersifat otonom dan tidak ditujukan kepada sikap lahir, tetapi ditujukan kepada sikap batin manusia. Batinnya sendirilah yang mengancam perbuatan yang melanggar norma kesusilaan dengan sanksi tidak ada kekuasaan, di luar dirinya yang memaksakan sanksi itu kalau terjadi pelanggaran norma etika, misalnya pencurian atau penipuan, maka akan timbul dalam hati nurani si pelanggar, rasa penyesalan, rasa malu, takut dan manusia bersalah.

Norma etik dan norma moral menjadi acuan manusia dalam berperilaku. Dengan norma etik manusia dapat membedakan mana perilaku yang baik dan mana perilaku yang buruk. Manusia dituntut untuk senantiasa berbuat baik sesuai dengan kodratnya, karena semua perilaku atau tindakan perbuatan, manusia akan dipertanggung jawabkan kepada Tuhan. Dan barang siapa mengharap perjumpaan dengan Tuhannya, maka hendaklah dia berbuat baik dan mengerjakan amal sholeh dan janganlah mempersekutukan seorangpun dalam beribadah kepada Tuhannya. Artinya hanya kepada Allah kamu bertawakkal, jika kamu benar-benar orang yang beriman. Karena barang siapa yang bertawakkal kepada Allah, maka dialah yang akan mencukupinya.

Jika manusia memahami tentang pahala berbuat baik, maka sesungguhnya mereka senantiasa berlomba-lomba dalam mengerjakan kebaikan-kebaikan serta mereka berdo'a kepada Tuhan dengan penuh Rahmat dan mereka cemas atas siksa Tuhan akibat dosa dari perbuatan manusia. Manusia harus menyadari diri dalam hubungannya dengan orang lain: manusia harus mengingat kebaikan orang lain kepada dirinya dan mengingat kebaikan dirinya kepada orang lain dan melupakan keburukan orang lain kepada dirinya dan melupakan keburukan dirinya kepada orang lain.

Sultan Muhammad Idrus Kaimuddin menasehati dirinya agar senantiasa mengajari dirinya sendiri. Mengajari diri sendiri adalah lebih baik daripada diajari seribu orang guru. Ia juga menasehati dirinya agar senantiasa menyayangi diri sendiri, sebab menyayangi diri sendiri adalah lebih baik daripada disayangi orang lain. Selain itu, menasihatkan pula agar jangan mengikuti kehendak hawa nafsu, kecuali yang dinamakan nafsu radiyah dan murdiyah. Hal ini disuratkan dalam teks di bawah ini: 


\section{Bahasa Wolio}

Ee karoku yada-yadari karomu

Nafusumu ßega-ßega yuyoseya

Tabeyanamo nafusu rayudiyah

Nafusu sarongi marudiyah

Mosarowu guru ßemoyadariko

Yinda molawana yada-yadarikaromu

Motuyapa kasina miya yitu

Yinda ßeyakawa kasina yi karomu

\section{Terjemahan}

Wahai diriku, ajar-ajarilah dirimu

Nafsumu jangan terlalu ikuti

Kecuali nafsu radiyah

Nafsu yang dinamakan mardiyah

Walau seribu guru yang mengajarimu

Tiada bandingnya mengajari diri sendiri

Walau bagaimana kasih orang itu

Tiada bandingnya mengasihi diri sendiri

Sumber: (Laniampe, 2012: 17)

b. Tazkiyatun Nafs (menyucikan diri) dan larangan berbuat sombong

Mensucikan Diri merupakan jalan yang harus ditempuh oleh manusia agar senantiasa terjaga dari penjakit hati, lemah iman, dan sebagainya. Mengenai masalah ini Sultan Muhammad Idrus menasihati dirinya agar senantiasa mensucikan diri. Ia juga menasihatkan agar jangan merendahkan dan memandang enteng orang lain. Yang paling utama adalah selalu memikirkan kerendahan diri sendiri. Sesungguhnya manusia dan mahluk lainnya tidak berbeda asal kejadiannya, yaitu beasa dari setetes air. Demikian pula kelak akan mati, didalam tanah akan bercampur dengan tanah kuburannya. Hal ini disuratkan di bawah ini:

\section{Bahasa Wolio}

Ee karoku yincamu pekang kiloya

Nganga randamu boli yumanga pisaki

Fikiriya katambena karomu

Yuwe satiri Banamo minamu

Simbayu duka kadidi yanamako yitu

Yi nuncana tana nayile yuhancurumo

Yuposalomote tana koburumu

\section{Terjemahan}

Wahai diriku, sucikanlah dirimu

Niatmu jangan merendahkan orang

Dan juga jangan memandang enteng

Pikirkanlah kerendahan dirimu

Air setetes awal kejadianmu

Seperti juga mahluk lainnya

Didalam tanah kelak engkau akan hancur

Bercampur dengan tanah kuburmu

Nasihat di atas berisi larangan untuk setiap manusia untuk tidak bersikap sombong. Dalam konsep ajaran Islam melarang yang namanya berlaku sombong, tidak akan masuk seseorang jika dalam hatinya terdapat kesombongan, sedangkan yang patut berlaku sombong hanya Allah SWT, karena Allah maha segala-galanya. 
c. Jangan membual dan menfitnah

Menurut konsep Islam bahwa penyebar fitnah tidak akan masuk surga, Hudzaifah ra, menyatakan, Muhammad Rasulullah SAW bersabda, "Tidak akan masuk surga orang yang suka menyebar fitnah" (HR Bukhori). Sultan Muhammad Idrus Kaimuddin menasehati dirinya agar tidak memabukkan kesenangan dunia. Yang paling penting dipikirkan adalah perbuatan baik apa yang harus dilakukan terhadap sanak keluarga dan para sahabat (Syamsul, 2008; 428). Apabila kematian telah menjemput, maka berpisahlah dirinya dengan mereka itu. Hal ini disuratkan dibawah ini:

\section{Bahasa Wolio}

Ee, karoku, ßoli yumangabuya-buya

Temo duka ßoli yumangahumbu-humbu

Kadakina tabuya-buya rangata

Hari kiyama nayile ßeyu marimbi

Kadakina tahumbu miya rangamu

Yokadakina yuyala meya yingko

Yokalapena posaleya yinciya

Hari kiyama delamu ßeya totumu

\section{Terjemahan}

Wahai diriku, jangan suka membual

Dan juga jangan menfitnah

Kejelekannya sangat besar

Pada hari kiamat akan dihukum

Kejelekanmu membual sesamamu

Keburukannya kamu yang ambil

Kebaikannya dia yang ambil

Pada hari kiamat lidahmu akan dibakar

\section{d. Berkata jujur}

Sultan Muhammad Idrus menasihati dirinya agar jangan memakai kebohongan yaitu mengucapkan sesuatu dengan tidak jelas. Apabila telah memakai kebohongan, maka binasalah pada negeri yang dua yaitu dunia dan akherat.Ia juga menasehatkan, bila bermain-main maka jangan melampaui batas, kecuali dengan seisi rumah. Yang paling pokok adalah harus selalu berhati-hati mendiami dunia ini. Mengerjakan kebaikan itu pada hari kemudian akan mendapat perlindngan pada Tuhan. Hal ini disuratkan di bawah ini:

\section{Bahasa Wolio}

Ee karoku ßoli upeka pewuli Aboasaka saro inda motindana Barangkala upekemo incia yitu Amadakimo i lipu rua anguna Neu kaßonga ßoli upolalo sara Tontama kea laengana moragoa Neu kaßona podo sabu-sabutuna

\section{Terjemahan}

Wahai diriku, jangan memakai kebohongan Mengucapkan sesuatu yang tidak jelas

Kalau telah memakai seperti itu

Binasalah pada negeri yang dua

Dan bermain-main jangan melampaui batas

Perhatikan yang wajar

Bila bergurau batasbilah 
Upekalape incana mia rangumu

Tabeanamo te antona ßanuamu

Inda pokia nea tolaße saide

Upatotapu rouna pomananea

Upekatangka sarona pomusiraha

Ijitihadi umbore i dunia

Nunua mpu saro imalapeaka

Sio-siomo Opu apaliharaku

I hura-hura naile muri-muriana
Perbaiki hati sesamamu

Kecuali dengan seisi rumahmu

Tidak apa bila kelewat sedikit

Menetapkan muka biasa satu dengan yang lain

Menguatkan perkenalan satu dengan yang lainnya

Berhati-hatilah mendiami dunia ini

Telusurilah yang namanya kebaikan

Mudah-mudahan tuhan memeliharaku

Pada keributan di hari kemudian

Sumber: (Laniampe, 2012: 24)

e. Jangan memakai kebohongan

Jujur, merupakan bagian dari iman. Muhammad SAW bersabda:" tidak iman bagi orang yang tidak jujur dan tidak dapat dipercaya (tidak dapat menunaikan amanat). Dan tiada agama (iman) bagi orang tidak dapat dipegang janjinya." (HR. Achmad bin Hanbal, dari Anas bin Malik ra). Berkata-kata apa adanya, Sultan Muhammad Idrus menasihati dirinya agar senantiasa mengeluarkan kata-kata apa adanya. Menurut banyak berkata, dapat merusak hubungan baik dengan sesama.Akan tetapi bila kata-kata itu mengandung kebaikan menurut jalan agama di bolehkan seperti kata-kata dimuat dalam al-kitab seperti cerita mengenai kelebihan para nabi, keramatnya para wali dan kelakuan orang-orang saleh.Ia juga menasihatkan agar jangan memutuskan hal-hal yang wajib serta segala keperluan dirinya (Syamsul, 2006: 613-614). Hal ini disuratkan di bawah ini:

\section{Bahasa Wolio}

Ee karoki ßega-ßega mengkooni

Neukooni sabutuna hajati

Upekalape incana mia rangamu

Teupakawa makusuduna incamu

Kamengkooni dala imarimbiaka

Tabeanamo oni imalapeaka

Simbounamo tatula-tula kitabi

Te lelena kalaBiana nabi

Te lolitana karamatina wali

Te lakuna paimia salihi

Somana Boli uBotuki wajibu

Te malingu faralu $i$ karomu

Sumber: (La Niampe, 2012: 26)

\section{Terjemahan}

Wahai diriku, janganlah memboros kata

Bila berkata apa adanya

Berhati baiklah kepada sesamamu

Pertemukan maksud hatimu

Banyak berkata jalan merusakan

Kecuali kata yang membawa kebaikan

Seperti yang diceritakan dalam al-kitab

Dan berita kelebihan nabi

Dan cerita keramatnya para wali

Dan kelakuan orang-orang saleh

Asal jangan putuskan yang wajib

Dan semua keperluan pada dirimu. 
2. Tata Krama Terhadap Tuhan

Menetapkan Pendirian Kepada Tuhan, Meneguhkan Agama Islam, Mengikuti Ajaran Guru dan Menyayangi Sesama. Itulah nasehat Sultan Muhammad Idrus menasihati dirinya agar senantiasa menetapkan pendirian kepada tuhan yaitu dengan jalan meneguhkan ajaran agama Islam, mengikuti ajaran guru dan menyayangi sesama sebagaimna menyayangi diri sendiri. Demikian itulah terbitnya orang mukmin tinggal di dunia ini. Hal ini terdapat dalam teks naskah di bawah ini:

\section{Bahasa Wolio}

Ee karoku paihilasai incamu

Patotapua poaromu i Opumu

Pengkenisi agamana babimu

Te uosea kadarina gurumu

Mia rangamu masi akea mpuu

Simbou duka masiaka karomu

Tuamo yitu tuturana mu mini

Ambo-mbore i nuncana dunia si

\section{Terjemahan}

Wahai diriku, ihlaskanlah hatimu

Tetapkan pendirian pada tuhan

Peganglah agama nabimu

Dan ikuti ajaran gurumu

Orang sesamamu sayangi betul

Seperti menyayangi diri sendiri

Yang demikianitu terbitnya orang mukmin

Tinggal di dunia ini

Salah satu syarat diterimanya ibadah adalah niat ikhlas semata-mata karena Allah SWT, tanpa berniat untuk yang lain. Ikhlas hati untuk mengenal rahasia Tuhan atau Allah SWT, Sultan Muhammad Idrus menasihati dirinya agar senantiasa ihklas mengenang rahasia Tuhan. Rahasia Tuhan itu disimpan pada kalbu hamba yang dicintai-Nya, yaitu hamba-hamban-Nya yang saleh. Itulah yang disebut permata amal yang senantiasa memberi nur atau cahaya bagi semua prilaku yang baik. Hal ini disuratkan di bawah ini:

\section{Bahasa Wolio}

Ee karoku ihilasi atonepe

Rahasiana oputa mopewauko

Adikaka inca imasiaka

Nganga randana ßatua mosalihi

Ositumo jauharana amala

Mosuluwina ßari-ßari feli

\section{Terjemahan}

Wahai diriku, rasa ikhlaslah paling mulia

Rahasia Tuhan menciptakanmu

Menaruh pada hati yang diri-Nya

Lubuk hati hamba yang disayangi-Nya

Ikhlas rahasia yang tersembunyi

Pada kalbu hamba yang saleh

Di situlah permata amal yang menyinari semua perilaku 


\section{Tata Krama Profesi}

Menurut konsep dalam Islam bahwa setiap manusia adalah pemimpin. Maka setiap pemimpin akan dimintai pertanggung jawabnya. Berkaitan dengan kedudukan dan amanah member nasehat bahwa jangan mengutamakan kekuasaan dan kebangsawan. Sultan Muhammad Idrus menasihati dirinya agar jangan mengutamakan kekuasaan dan kebangsawanan. Keduanya itu semata-mata hanya kebesaran dan hiasan dunia.Yang harus diutamakan adalah hati nurani yang suci. Itulah yang akan kekal sampai pada hari kemudian. Hal ini disuratkan dibawah ini:

\section{Bahasa Wolio}

Ee karoku, fikiri mpu-mpu

Kakawasa tangkanamo yi diduniya

Yokalaki tangkanamo yi weyi

Te malingu kabelokana duniya

Yakawaka nayile muri-murina

Yamapupumo ßari-ßariya situ

Tangkanamo totona yinca mangkilo

Bemolagina naliye muri-murina

\section{Terjemahan}

Wahai diriku, pikirkan betul-betul

Kekuasaan hanya ada di dunia

Kebangsawan hanya ada di sini

Dan segala kebesaran hiasan dunia

Sampai pada hari kemudian

Habislah dunia itu

Hanya hati nurani yang suci

Yang kekal abadi

Nasehat di atas sesuai dengan hadits Nabi dari Ibnu Abbas ra, menuturkan, Muhammad Rosulullah SAW bersabda: "Amal kebaikan sehari dari seseorang pemimpin yang adil lebih baik dari pada ibadah selama enam puluh tahun" (HR.Thobrroni). Sumbangan terbesar Sultan Muhammad Idrus Kaimuddin dalam bidang birokrasi di kesultanan Buton yaitu membuat Undang-Undang pemerintahan berisi tentang aturan dan adat istiadat dalam pemerintahan di kesultanan Buton.

Ciri rohani dari tasawuf memperkuat kekuasaan, dalam sistem kekuasaan di Kesultanan Buton, penguasa, khususnya sultan dipercayai memiliki ciri rohani. Ciri rohani ini merupakan salah satu unsur yang menimbulkan kharisma pada diri penguasa. Seorang Sultan dipercaya memiliki berkah karena mampu melakukan empat, hal yaitu: mampu mengetahui keadaan rakyatnya dengan ilmu batinnya; mampu menunjukan kesalahan rakyatnya yang nyata dan tersembunyi; ia mampu menjadi raja Wolio lahir dan batin; dan mampu bersikap adil (Yusran, 2011: xxi). 
4. Tata Krama di bidang Tarbiyah atau Pendidikan

Dalam Islam mengenal nilai-nilai pendidikan, pendidikan adalah suatu proses dan sistem yang bermuara dan berujung pada pencapaian suatu kualitas tertentu. Pendidikan pada umumnya dan khususnya pendidikan Islam, tujuannya tidaklah sekedar proses alih budaya atau ilmu pengetahuan (transfer of knowledge) tetapi juga proses nilai-nilai ajaran Islam (transfer of value).

Tujuan pendidikan Islam menjadikan manusia bertakwa, manusia yang dapat mencapai al falah, kesuksesan hidup yang abadi, dunia dan akhirat (muflihun). Selain itu tujuan pendidikan Islam adalah mengembangkan manusia yang baik, yaitu manusia yang beribadah dan tunduk kepada Allah SWT serta mensucikan diri dari dosa. Untuk mewujudkan itu semua pada masa lalu para pendakwah Islam khususnya para ulama mendirikan pondok pesantren dengan menerapkan metode tertentu pada sekolah tersebut. Setelah Islam menjadi agama masyarakat dan kokoh mengakar di kawasan Indonesia, maka sebagai payung pengayom dibutuhkan adanya suatu pemerintahan yang mengatur kehidupan umat Islam. Kesadaran akan adanya pemerintahan yang dapat menjadi pelayan umat ini, dimunculkanlah kerajaan-kerajaan atau keratonkeraton (keratuan). Kerajaan atau keraton yang mengurus masyarakat Islam ini berupaya dijalankan menurut ajaran Islam, sesuai dengan kemampuannya. Bahwa pesantren di Kesultanan Buton sebagai syiar dakwah Islamiyah, juga sebagai tempat pendekatan antara ulama, raja dan rakyatnya.

Berikut nasehat beliau bahwa sering mendengarkan pengajaran. Sultan Muhammad Idrus menasihati dirinya agar senantiasa mendengarkan pengajaran, terutama pengajaran dari orang-orang saleh. Ia menegaskan, yang namanya ajaran untuk kebaikan baik untuk didengarkan meskipun asalnya dari mulut orang gila bahkan dari mulut binatang sekalipun. Sabda Nabi Muhammad SAW: "ambillah kalian ilmu itu meskipun berasal dari mulut binatang demi menuju jalan kebaikan”. Mengenai masalah ini terdapat dalam nasehat Sultan berikut ini:

\section{Bahasa Wolio}

Te umenturu rango oni malape

Kadarina paimia salihi

Boli panganta ßeu rango kadari Bara salana betao bahagiamu

Osea mpu saro I malapeaka Malingiaka oni i rangomuitu

\section{Terjemahan}

Seringlah dengar kata-kata yang baik Ajaran dari orang yang saleh Jangan bosan mendengarkan ajaran Siapa tahu untuk kebahagiannmu Ikuti betul yang namanya kebaikan Segala kata yang engkau dengarkan itu 
Kawanamo mina i momagilana

Neo itumo saro imalapeaka

Akonimo hatimi rusuli

Muhammadi saidina anbia

Alea komiu katau itu

Hengga katau i mulutina binata

Neo itomu giu imalapeaka
Walaupun asalnya dri orang gila Kalau sudah itu yang menjadi kebaikan Bersabda rasul yang penghabisan Muhammad penghulu segala nabi Ambillah kalian ilmu itu Meskipun dari mulut binatang

Bertawakal dan berpegang teguh pada kata-kata Nabi atau Hadits Nabi Muhammad SAW. Sultan Muhammad Idrus menasihati dirinya agar senantiasa bertawakal dan berpegang pada kata-kata nabi.Dikatakan bahwa dunia ini adalah tempatnya kesalahan. Banyak sekali racun yang membinasakan. Racun itu berasal pendengaran, penglihatan dan penciuman. Hal itulah yang sampai pada perasaan yang senantiasa menghukum hati yang baik. Nafsu yang tidak baik berada diantara kedua tulang rusuk dan itulah musuh yang kekal.Untuk melawan musuh seperti itu, harus melaksanakan dzikir sesering mungkin dan hati senantiasa dibuat agar takut kepada tuhan yang Mahakuasa. Hal ini disuratkan dibawahkan:

\section{Bahasa Wolio}

Ee karoku tawakala mpu-mpu

Pengkenisi ajanji mina I nabi

Dunia si mboresana karimbi

Aßari mpu racu ibinasaka

Ominana racu ibinasaka

Oporango, opokamata opebou

Si tumo mokawana i manisi

Morimbitina incamu momalapena

Mboresana nafusu momadaki

Polotana rua mbali lupe-lupe

Si tumo ewalina molagina

Motopenene incana karota si

Kaewangina ewali incia itu

Zikirillahi menturu akea mpu

Incamu itu pekakaia mpu

Iparintana Oputa Momakana

\section{Terjemahan}

Wahai diriku, tawakallah betul-betul

Peganglah janji nabi

Dunia ini tempatnya kesalahan

Banyak sekali racun yang membinasakan

Asalnya racun yang membinasakan

Pendengaran, penglihatan, penciuman

Itulah yang sampai pada perasaan

Yang menghukum hati yang baik

Tempat nafsu yang tidak baik

Di antara kedua tulang rusuk

Di situlah musuh yang kekal

Yang baik pada diri kita

Untuk melawan musuh seperti itu

Berzikirlah sesering mungkin

Hatimu berbuatlah menjadi takut

Pada perintah tuhan yang Mahakuasa 
d. Nasehat dan ijitihad Sultan Idrus Kaimudin Mengenai Hari Kiamat

Nasehat berasal dari bahasa arab kata nashihah (ketulusan). Kata kerja nashihah berarti mencitai secara tulus. Dengan demikian, yang dimaksudkan nasehat tersebut adalah iman kepada Allah secara tulus. Nasehat bagi kitab-Nya yaitu harus mengimani al Quran dan kitab-kitab yang diturunkan sebelumnya nasehat bagi Rasulnya berarti harus membenarkan risalahnya. Beriman pada atas hari akhir merupakan rukun Iman yang keenam, Sultan Muhammad Idrus Kaimuddin memberikan wejangan agar mempercayai hari akhir, Sultan Muhammad Idrus menasehati dirinya agar senantiasa memperkuat pegangan dan itikad. Ketika kematian datang menjemput, itulah pertanda datangnya hari kiamat. Itulah yang disebut peristiwa yang menyebabkan kesusahan semua hamba. Pada saat itu, semua amal akan ditimbang dengan mizan, yaitu timbangan yang benar. Mengenai masalah ini dijelaskan dibawah ini:

\section{Bahasa Wolio}

Ee karoku pekatangka pengkenimu

Itikadimu ßoli akadoli-doli

Matemo itu pada aumbatikomo

Hari kiama pada alahirimo

I Weitumo huru-hara momaoge

Kasukarana Bari-Baria batua

Atotimbangi ßari-ßaria amala

I mizani kaloesa mobanara

\section{Terjemahan}

Wahai diriku, perkuatlah peganganmu

Etikadmu jangan berubah

Kematian kelak akan mendatangimu

Hari kiamat nanti akan hadir

Di situlah peristiwa yang besar

Kesusahan semua hamba

Akan ditimbang semua amal

Dengan mizan timbangan yang benar

Adzab dan hari kiamat akan datang, Sultan Muhammad Idrus menasihati dirinya agar senantiasa memikirkan datangnya azab dan hari kiamat. Ketika, dunia akan gelap gulita. Sedikit pun tidak da lagi cahaya. Itulah kehidupan sesudah mati yang menyebabkan kesusahan hamba Tuhan. Umat Islam saling memaafkan disertai tangisan yang sekeras-kerasnya, sambil menantikan sebuah takdir dari Tuhan. Mereka bertangisan karena memikirkan bagaimana kelak nasib mereka setelah tiba hari kiamat. Hal ini disuratkan di bawah ini:

\section{Bahasa Wolio}

Ee karoku ombu pada aumbamo Bea bukea naile dunia si Amalalanda, agalapu, apoposa

\section{Terjemahan}

Wahai diriku, azab sudah akan datang Akan memenuhi dunia

Akan gelap, akan gulita dan sangat gelapnya 
Mo saide indamo te kainawa Itumo duka kaheruana batua Pokeni lima paimia Isilamu Te akoni manga incai yitu Inciamo si zamani betamatemo Potangisimo paiaka Isilamu Atangi mpu aoge-oge incana Audanimo janji mina i nabi Hari kiama pada aka aumbamo Salana manga poma-mafuaka Nedangia te salana mangengena Apentamo hukumu mina i Opu Opeamobara bemokorouna si Atangi mpu bari-baria situ Audanimo karunggana alamu Te afikiri bangu i hari kiama Betuapa naile ingikita si
Walau sedikit tidak ada lagi cahaya Itu pula kesusahan hamba Berjabatan tangan para umat Islam Dan berkata mereka itu Itulah kehidupan sesudah mati Saling bertangisan para umat Islam Menagis dengan sekeras-kerasnya Mengingatkan janji nabi Hari kiamat sudah akan datang Kesalahan diantara mereka saling memaafkan Kalau ada kesalahan yang lampau Menantikan hukum dari Tuhan Bagaimanakah wujud kita nanti Menangislah dengan sejadi-jadinya Mengingat akan kehabisan alam Memikirkan keadaan di hari kiamat Bagaimana kelak kita ini

Sifat dunia bersifat fana atau tidak abadi, menurut Sultan bahwa Dunia kelak akan hancur. Mengenai masalah ini Sultan Muhammad Idrus menasihati dirinya agar senantiasa mempercayai bahwa kelak dunia ini akan hancur. Pertanda kehancuran itu akan diawali dengan datangnya angin kencang yang akan menghancurkan semua gunung yang disertai keringnya lautan serta gempa yang sangat dahsyat. Pada saat itu, semua ciptaan didunia akan fanah, kecuali Allah yang tetap hidup kekal, alam akan kembali seperti sebelum diciptaakan. Peristiwa seperti akan berlangsung selama 40 tahun, setelah itu barulah akan ada lagi. Itulah yang disebut dengankeadaan yang kekal. Hal ini disuratkan di bawah ini:

\section{Bahasa Wolio}

Ee karoko keniaka mea mpuu Dunia sii padaaka amarunggamo Ngalu maka padaaka tumpumo Bemorunggana bari-baria kabumbu Tee amatuu bari-baria andala Tee akolendu soma-somana kakaa Osiitumo karunggana alam

\section{Terjemahan}

Wahai diriku pegang teguh betul

Dunia ini kelak akan hancur

Angin kencang jelas akan ada

Akan menghancurkan semua gunung

Dan akan kering semua lautan

Dan gempa yang sangat dasyatnya

Itulah kehancuran alam 
Kapupuana bari-baria batua Afanaamo malingu kadaangia Somoo opu molagina mobakaa Alamu sii ambulimo anainda Simbou duka kadaangia i azali Pata pulu taona tua siitu Beafana bari-baria batua Simpoomini ambuoli adaangia Osiitumo kadaangia molagi
Penghabisan semua mahluk

Fanalah semua keadaan

Hanya Tuhan yang kekal abadi

Alam ini akan kembali tiada

Seperti keadaan sebelum lahir

Empat puluh tahun lamanya demikian itu Akan fana semua hamba

Baru lagi akan kembali ada Itulah keadaan yang kekal.

Nasehat beliau berkenaan cerita mengenai peristiwa pada hari kemudian, Sultan Muhammad Idrus kaimuddin menasihati dirinya agar mendengarkan cerita mengenai peristiwa pada hari kemudian. Dikisahkan pertama-tama turun hujan rahmat yang berasal dari 'arays yang langsung dari Tuhan. Hujan rahmat itu membasahi semua kuburan serta semua jasad yang telah hancur. Hujan itu pula yang membangkitkan semua hamba ciptaan-Nya. Pertama-tama yang duluan bangkit adalah malaikat yang empat, firman Tuhan: pergilah kalian ke surga mengambil mahkota yang mulia, semua pakaian yang mulia, bendera kebesaran Tuhan dan buraq untuk Nabi Muhammad. Nabi Muhammad adalah hamba yang dimuliakan, Rasul yang disayangi, oarang yang dikasihi oleh Tuhan, Ia juga dapat memberi syafaat kepada umatnya yang berdosa pada hari perhitungan (yaum al mizan) dan menyelamatkan umatnya dari siksa azab neraka.

Setelah para malaikat itu kembali dari surga, kemudian menelusuri kuburan Nabi Muhammad di padang masyhar. Setelah tiba di tengah-tengah padang masyhar, malaikat Jibril memanggil Nabi Muhammad "Di mana kuburmu wahai Muhammad? Tidak lama kemudian terbelahlah tanah kuburan Muhammad, lalu bangkit dari kuburnya. Ia duduk pada bagian kepala tanahnya sambil mengusap jenggotnya dan kepalanya serta seluruh badannya dari abu tanah kuburnya. Ia lalu bertanya kepada Malaikat Jibril, "Jibril, hari apakah sekarang ini?" jawab Jibril: inilah hari syafaatmu, kelebihan dari Tuhan untuk menyelamatkan umatmu yang berdosa. Nabi muhammad langsung mengucapkan salawat dan salam, kemudian bertanya lagi pada Jibril, "Di mana umatku ini? Barangkali sudah dalam siksaan? Jawab Jibril, "umatmu belum ada yang bangkit", haram bila ada manusia yang lebih dahulu bangkit yang mendahului engkau Muhammad dan itulah tanda kemuliaanmu". Tidak lama kemudian, bangkit pula Abu Bakar di susul Umar. Keduanya sahabat Nabi Muhammad. Mereka bertiga lalu mengenakan 
pakaian surga yaitu mahkota, izar dan sepatu. Tumpangan mereka adalah buraq yang tercepat yang dipilih dari surga. Hal ini juga merupakan tanda kemuliaan Tuhan kepada hamba-Nya yang tiga. Kemudian mereka bertiga berjalan, lebih dahulu Nabi Muhammad kemudian Abubakar, kemudian Umar, mengikuti para barisan malaikat, yang diikuti para pengawalnya. Mereka berjalan-jalan, di padang masyhar yang luas. Ketika itu Nabi Muhammad berjalan sambil memperhatikan umatnya yang akan bangkit.

Malaikat Jibril meniup sangkakalanya untuk membangunkan semua isi kubur. Ketika itu semua bangkit baik muslim maupun kafir termasuk seluruh binatang. Mereka bangkit di padang masyhar. Setelah melihat mereka bangkit, Tidak lama kemudian bermunculan sekelompok manusia memenuhi berbagai tempat. Nabi Muhammad lalu bertanya kepada Malaikat Jibril, "Jibril, dimana umatku? . Jibril kemudian berkata: "Muhammad, disanalah umatmu", lalu Nabi Muhammad pergi menemui mereka dan bertanya kepada umatnya, "Bagaimana perasaan kalian tinggal di dalam kubur?, Mendengar pertanyaan itu, seluruh umat Muhammad menangis, Nabi Muhammad pun juga menangis, pertanda sayang kepada umatnya. Kisah tersebut disuratkan di bawah ini:

\section{Bahasa Wolio}

Ee karoku rangoa tula-tulana

Kadangia naile muri-murina ßaßana akowau rahamati Asapo mai minaka $i$ arasi Apepatai ßari-ßaria koburu Amemeiki paikaro mobinasa Orahamati amina $i$ Opu rahimu Sumber: (La Niampe, 2012: 28)

\section{Terjemahan}

Wahai diriku, dengarkanlah ceritanya

Keadaan pada hari kemudian

Mula-mula hujan rahmat

Turun naik berasal dari aras

Menyeluruh pada semua kuburan

Membasahi semua jasad yang binasa

Rahmat itu berasal dari Tuhan Rahim.

\section{Nasehat dan Ijitihad Sultan Idrus Kaimuddin terhadap Bahaya Dunia}

Rasulullah menyebut dunia adalah penjara bagi orang mukmin. Namun sebagai imbalan ketaatan manusia yang beriman kepada Allah SWT, kelak akan memperoleh surga yang kenikmatannya jauh lebih sempurna dari segala kenikmatan dunia. Sultan menyeru kepada manusia agar jangan terbuai dengan kesenangan dunia, yang paling penting dipikirkan adalah perbuatan baik apa yang harus dilakukan terhadap sanak keluarga dan para sahabat. Apabila kematian telah menjemput, maka terpisahlah dirinya dengan semua orang. Mengenai masalah ini dijelaskan di bawah ini: 


\section{Bahasa Wolio}

Ee, karoku ßega-ßega yumalango

Yinda yufikiri kampodona umurumu

Matemo yitu tayomo papogako

Te malingu saßara manganamu

Temo duka saßara musiharamu

Wutitinayi tawa mosaganana

\section{Terjemahan}

Wahai diriku, janganlah mabuk

Tidakkah engkau pikirkan sisa umurmu?

Kematianlah yang akanmenceraikanmu

Dengan semua anakmu

Dan juga dengan semua kenalanmu

Famili atau yang lain-lainya

Menurut Sultan dunia memiliki kejelekan fitnah dunia, Sultan Muhammad Idrus Kaimuddin menasihati dirinya agar menghindari kejelekan fitnah dunia. Fitnah dunia bagaikan berlayar yang tidak kenal di negeri tempat berdagangnya. Dunia ini adalah tempat yang berubah, sebagaimana telah diuraikan oleh hadits nabi. Siapa-siapa yang tidak mempercayainya sesungguhnya orang itu kafir. Hal ini disuratkan di bawah ini:

\section{Bahasa Wolio}

Ee karoku togasaka mpu-mpu

Yokadakina fitanan duniya

Pamana ßose padaka yuhelamu

Yinda ßeyulagi yi lipu podagamu

Duniya si mboresa momarungga

Totula-tula yi Haditsina nabi

Yincema-yincema miya moperawasiya

Satotuna miya yitu kafiri

\section{Terjemahan}

Wahai diriku, berpasrahlah betul-betul

Kejelekan fitnah dunia

Bagaikan berlayar tidak lama lagi bertolak Tidak ada kekal di negeri perdaganganmu

Dunia ini tempat yang berubah

Diceritrakan di dalam hadits nabi

Siapa-siapa tidak mempercayainya

Sesungguhnya orang itu kafir

\section{Peran Sultan Muhammad Idrus Kaimudin dalam Pengembangan Ajaran Islam dan Budaya Buton}

Proses relasi antar pendukung dua budaya dialami oleh Muhammad Idrus Kaimuddin pada saat menjadi santri di pesantren Zawiyyah. Terlahir dari keluarga Sultan Buton, Muhammad Idrus Kaimuddin I sejak kecil telah mengenal budaya Wolio (Buton). Keturunan seperti keluarga Muhammad Idrus Kaimuddin adalah pendukung dan pengembang budaya Wolio, bahkan semua pegawai atau pejabat kesultanan memiliki tanggung jawab melestarikan budaya Buton.

Pendidikan pesantren Zawiyyah menjadi pendukung budaya Islam yang di serap Muhammad Idrus Kaimuddin. Maka terjadilah proses pembelajaran 
hasrat maupun emosi keagamaan dalam diri Muhammad Idrus kaimuddin. Mengenai masalah keimanan pada Allah SWT, pengaruh pendidikan Islam lebih kuat disbanding pengaruh lingkungan keratin. Sehingga Muhammad Idrus Kaimuddin berusaha menentang dan meluruskan pemahaman yang cenderung syirik atau menyekutukan tuhan. Beliau mengkritik beberapa kepercayaan yang dapat membawa kemusyrikan seperti upacara dengan mengggunakan binatang yang disembelih.

Pada saat berhadapan dengan budaya Buton yang menyimpang dari prinsip tauhid menimbulkan pergumulan pemikiran Sultan Muhammad Idrus kaimuddin. Muhammad Idrus Membangun Masjid Baadia. Seperti sudah diuraikan bahwa Muhammad Idrus sejak masa kecilnya diasuh dan dibesarkan oleh kakeknya (Sultan Kaimuddin Tua La Jampi). Kakeknya inilah yang mendidiknya dalam hal keagamaan. Pengetahuan keagamaan terbawa-bawa sampai Muhammad Idrus menjabat sebagai Sultan. Dalam kedudukannya sebagai Sultan ditumpahkannya segala pengetahuanya itu kepada masyarakat yang dinaunginya. Tetapi beliau jalankan dengan penuh kehati-hatian. Dengan kesadaran dan penuh kerendahan hati, sehingga dengan didikan beliau berhasil dalam mengembangkan kesatuan dan persatuan yang berlandaskan ilmu keagamaan.

Tidak saja di dalam Keraton Muhammad Idrus menjalankan syariat agama Islam, tetapi sampai menyeluruh ke pelosok pedesaan dalam kerajaannya. Sejalan dengan pesatnya pengetahuan agama, Muhammad Idrus, mewajibkan masyarakat Keraton untuk memakai bahasa Arab sebagai bahasa pergaulan sehari-hari. Kewajiban ini dihubungkan pula dengan keharusan untuk mengetahui makna-makna ayat-ayat al Quran, sebab menurut beliau ayatayat yang dibaca itu harus diketahui maknanya supaya berguna. Dan dengan mengetahui Bahasa Arab akan lebih memudahkan mempelajari ilmu agama melalui buku-buku karangan para ulama besar Islam. Pada zaman Muhammad Idrus banyak masuk buku-buku karangan orang-orang besar Islam di Buton melalui para pedagang. Oleh karena masyarakat mengenal Bahasa Arab serta melalui pembacaan buku-buku, maka tidaklah mengherankan kalau ilmu pengetahuan beragama berkembang dengan pesat dikalangan masyarakat.

Gelora rakyat untuk belajar dan mengetahui ilmu keagamaan sedemikian mendesak, menjadikan tempat-tempat peribadatan serta pengajian perlu ditambah, Muhammad Idrus membangun sebuah Masjid di Baadiah sebagai Masjid keluarga. Ditempat ini selain melaksanakan sholat, juga diadakan pengajian bagi anak cucunya serta pengikut-pengikutnya dan Muhammad Idrus 
senantiasa memimpin shalat lima waktu dan sekali-sekali turut menyaksikan pengajian anak-anak.

Pembangunan Masjid Baadia diperkirakan berkisar pada tahun \pm 1825 . Maka terkenallah tanah Wolio dengan beberapa masjid:

1. Masigina Wolio- Masjid Kerajaan terdapat dalam benteng Keraton sekarang;

2. Masigina Sarawolio - terdapat dikampung Sarawolio - tidak ada lagi, tinggal bekasnya dalam benteng Sarawolio

3. Masigina Baadia - terdapat di desa Baadia, masi ada dipergunakan masyarakat Baadia;

Bentuk arsitektur masjid tersebut merupakan perpanduan Islam dengan unsur budaya Wolio. Pada satu surat wasiat Muhammad Idrus Kaimuddin, beliau berpesan kepada penduduk Baadia supaya Masjid Baadia jika sudah roboh agar dibangun kembali pada tempatnya dan supaya selalu digunakan bersembahyang oleh anak cucunya. Menurut sumber oral tradition bahwa masjid Baadia dibangun sesuai dengan bentuk masjid Nabi di Madinah. Jendela sampai banyaknya tiang jumlahnya sama. Masjid yang dimaksud adalah masjid yang dibangun Nabi sewaktu hari pertama tiba dari perjalanan hijrahnya dari Mekkah, dipakai Shalat bersama pengikut muhajirin. Itulah sebabnya antara lain Muhammad Idrus dengan pesannya supaya jangan dirubah bentuknya. Boleh memperbaiki misalnya atapnya, lantainya, tetapi besar dan bentuknya tidak diperkenankan oleh beliau. Menyempurnakan aturan kerajaan yang tidak sesuai lagi dengan perkembangan ilmu pengetahuan beragama, diadakan penyempurnaan atau penyesuaian atau dihapuskan sama sekali. Beberapa kebijakan yang ditempuh diantaranya disebutkan seperti:

1) Penghapusan botu bitara dan kasapuina lante

Botu Bitara adalah suatu pembayaran wajib karena adat, bagi mereka yang berperkara, barangkali hampir sama dengan sekarang "pembayaran uang meja”. Buto Bitara juga dikenakan kepada mereka yang ingin membagi-bagi harta peninggalannya. Dapat diterangkan bahwa menurut adat dalam pembagian harta warisan yang dilakukan oleh beberapa orang tua yang diminta oleh ahli waris yang bersengketa, sedah menjadi ketentuan hukum adat bahwa barang-barang yang tidak mempunyai pasangan atau yang tidak dapat dibagi di antara ahli waris, menjadi hak orang-orang tua yang mengadakan pembagian. Bersumber dari adat inilah Muhammad Idrus mengadakan penghapusan Botu Bitara. Dasar-dasar yang digunakan sebagai penghapusan Botu Bitara tersebut oleh Muhammad Idrus Kaimuddin, bahwa dalam pelaksanaannya dapat 
membawa orang tua yang mengadakan pembagian kepada jalan yang menyesatkan diri mereka sendiri. Bahwa tidak mustahillah kalau ada diantara mereka itu, adanya usaha untuk mendapatkan keuntungan pribadi. Yang bersandar kepada hawa nafsu kepentingan diri. Selanjutnya Muhammad Idrus berkata bahwa "orang yang mengambil keuntungan diri melaksanakan suatu tugas pekerjaan, terlebih kalau karena jabatan adalah suatu perbuatan yang sangat tercela sehingga dilarang oleh agama”. Firman Allah SWT "Wa taraa katsiran minhum yusaari'uuna fil ismi wal 'udwani wa ahlihimus akhta labi'samaa kanuu ya'maluna" artinya "ketahuilah (ya Muhammad) dan engkau melihatnya banyak mereka kaum munafik cepat-cepat melakukan dosa".

Imam Baedlawi berkata, utang seperti disebut ialah dusta (kapee-pewuli) dan mereka itu sering membuat kezaliman terhadap sesamanya dan memakan yang haram. Mufassirnya berkata: "itu seperti riswa, yaitu mengambil keuntungan dalam mengadili sesamanya". Sabda Nabi SAW "La ana allahu al rashiy wal murtashiy fil hukmi" artinya "Allah melaknat orang yang memberi dan orang yang menerima keuntungan di dalam mengadili sesamanya". Nabi SAW juga bersabda yang artinya "al Rashiy wa al murtashi fi an nar" (yang memberi dan menerima keuntungan itu dalam neraka).

2) Hak waris bagi anak perempuan dan anak laki-laki.

Sebagaimana diketahui bahwa menurut hukum Islam pembagian anak laki-laki dan anak perempuan adalah dua bagian anak laki-laki dan satu bagian anak perempuan. Itulah perbandingannya. Di masa kesultanan Muhammad Idrus ketentuan itu diubah dan disesuaikan dengan keadaan, sehingga terjadilah pembagian anak laki-laki dan anak perempuan mendapat bagian yang "sama" tidak ada perbedaan. Ketentuan ditetapkan dengan bersandar pada hak anak terhadap orang tua, yang tidak ada bedanya, kemudian asal kejadian mereka dari orang tua (ibu bapak) juga tidak berbeda dan berasal daripada air yang hina. Itulah dasar yang pertama, kemudian sejalan juga dengan perkembangan, Muhammad Idrus melihat bahwa kaum laki-laki dan kaum perempuan pada dasarnya mempunyai kewajiban yang sama terhadap kerajaan. Buktinya bahwa Sultan dan permaisuri keduanya sama berkewajiban dalam menegakkan kerajaan dan itu ditandai dengan keduanya sama dilantik yang dilakukan oleh menteri siolimbona. Suami dilantik oleh siolimbona laki dan permaisuri dilantik oleh isteri siolimbona yang bersangkutan. Dan jika kembali melihat kenyataan sekarang, dan itulah yang menjadi jawaban atas pertanyaan di atas. 
Kembali mengingatkan dengan peringatan Tuhan kepada manusia mengenai asal usul kejadian : "Huwa al ladziy khalakakum min nafsin maahidatin waja'ala minhaa zaujalaha liyaskuna ilaihaa". Dialah yang menciptakan kamu dari diri yang satu dan dari padanya Dia menciptakan isterinya, agar dia merasa senang kepadanya. Maka setelah dicampuri-Nya, isteri itu mengandung kandungan yang ringan, dan tentulah dia merasa ringan (beberapa waktu). Kemudian takkala dia merasa berat kedunya (suami isteri) bermohon kepada Allah, Tuhannya, seraya berkata: sesunguhnya jika Engkau memberi kepada kami anak yang saleh, tentulah kami termasuk orang-orang bersyukur”.

3) Orang yang melakukan perzinahan dikenakan hukuman yang berat

Hukum rajam itu benar ada dalam kitab Allah atas orang yang berzina baik pria maupun wanita, apabila ia muhshom dan ada saksi atas perbuatan itu atau dia hamil, atau dia mengaku" (HR. Bukhori, Muslim, Abu Dawud, Tirmidzi, dan Nasa'i). Berdasarkan dengan firman dan ini sama diwujudkan secara nyata dengan tidak memandang bulu, siapa saja ditindaki. Dalam ketegasannya itu Muhammad Idrus berkata bahwa firman dan haditslah yang menjadi dasar utama. Bertentangan dengan firman dan hadits harus dihukum setimpal dengan perbuatan. Dalam hubungan zina yang dalam adat dikatakan:

a. Pahalata yaitu perbuatan laki-laki dan perempuan terhadap anak, saudara, ibu dan lain-lain yang kesimpulannya tidak dibenarkan untuk kawin; hukuman yang dilimpahkan termasuk yang berat umumnya dengan hukuman mati;

b. Masalah yaitu melakukan hubungan dengan perempuan yang bersuami dikenakan hukuman dera. Perbedaan dengan pahalata adalah bahwa pahalata tidak dapat sama sekali untuk kawin sedangkan masalah kalau masih hidup dalam menjalankan hukuman dapat menikah setelah pernikahannya yang pertama diputuskan;

c. Zina, ialah hubungan laki-laki dan perempuan dengan tidak melalui pernikahan yang syah;

d. Pebula, adalah perhubungan yang dikarenakan kenakalan semata dari laki-laki. Bahwa pada masa lampau diwaktu terang bulan anak-anak muda mengambil kesempatan keluar rumah bersenang-senang. Bula dalam bahasa Indonesia sama dengan terang (bulan). Karena kenakalan itu terjadinya diwaktu terang bulan maka dikatakan pebula. Dihukum apabila ada pengaduan dari pihak-pihak yang bersangkutan. Tetapi pada umunya yang demikian ini dikawinkan saja untuk mencegah pertentangan-pertentangan keluarga. 
Landasan dalam al Quran antara lain: "Azzaniyatu wazzaaniy fajlidu kulla waahiddin minhumaa miata jaldah, walaa ta'huzkum bihi maa ra'fatun fiidiynillahi in kuntum tu'minuna billahi walyaumil akhiri wal yasyhad asaa bahuman taaifatun minal mu'minina". "Perempuan yang berzina dan laki-laki yang berzina, maka deralah tiap-tiap seseorang dari keduanya dari dera dan janganlah belas kasihan kepada keduanya mencegah kamu untuk (menjalankan) agama Allah, jika kamu beriman kepada Allah, dan hari akhirat, dan hendaklah pelaksanaan hukuman mereka disaksikan oleh sekumpulan dari orang-orang yang beriman”.

Kemudian selaku pegangan dalam peletakan keadilan, Muhammad Idrus tidak lupa mengingatkan dirinya dengan firman: "Innallahu ya'murukum an tuaddul amaanati ilaa ahlihaa wa idzaa hakamtum bainan naasi an tahkumu bil adli; innallahu kaana samiun basyiran". "Sesungguhnya Allah menyuruh kamu menyampaikan amanat kepada yang berhak menerimanya, dan (mengurusi kamu), apabila menetapkan hukum diantara manusia supaya kamu menetapkan dengan adil. Sesungguhnya Allah Maha Mendengar lagi Maha Melihat". Firman Allah: "Inna anzalnaa ilaika kitaaba bil haqqi litahkuma bainannasi biman araakallahu; walaa takum lil khainiyna khaniyma".

"Sesungguhnya Kami telah menurunkan kitab kepadaamu dengan membawa kebenaran, supaya kamu mengadili diantara mereka dengan apa yang telah Allah wahyukan kepadamu, dan janganlah kamu menjadi penentang (orang yang tidak bersalah) karena (membela) orang-orang yang berkhianat".

Demikian itu yang menjadi keharusan bagi pemimpin yang iman dalam menjalankan kebenaran dan keadilan. Keharusan bersikap adil dan tidak memihak dalam menetapkan suatu perkara. Ketegasan dalam tindakan hukum, Muhammad Idrus menjalankannya dengan penuh konsekuen diiringi dengan kenyataan. Melihat kenyataan inilah sehingga rakyat mematuhi sultannya dengan penuh kasih sayangnya karena tidak memandang tinggi rendahnya orang yang membuat kesalahan. Sampai pada diri sendiri Muhammad Idrus bertindak. Dan yang utama bagi mereka yang mempermainkan agama. Ada baiknya bila ungkap beberapa ketegasan-ketegasan Muhammad Idrus dalam tindakannya: Suatu waktu terjadi seorang anggota masyarakat yang berdiam di sekitar Baadia, sudah beberapa hari tidak kelihatan turut berjamaah di Masjid Baadia, maka diadakanlah penyelidikan. Diperoleh lah keterangan bahwa orang yang dimaksud sering kedengaran azan di rumahnya terutama pada waktu subuh, maka disuruhlah orang untuk mengintipnya. Kembali pemberitaan didapatkan bahwa yang bersangkutan di waktu subuh sebenarnya 
adzan. Tetapi, anehnya diketahui ia adzan sambil berbaring padahal ia tidak sakit. Demikianlah, karena orang itu terbukti hanya mempermainkan agama, maka dalam keputusan yang dilimpahkan kepadanya dikenakan hukuman mati dengan jalan dihukum mati yang dilaksanakan di depan Masjid Baadia, dihadiri segenap anggota masyarakat Baadia dan sekitarnya.

Muhammad Idrus juga pernah menjatuhi hukuman mati kepada pamannya sendiri, saudara sebapak dari ayahnya karena melakukan perbuatan yang sangat tercelah. Bahwa paman Muhammad Idrus tersebut yang bernama La Ode Afrid Lakina Mawasangka yang menurut laporan sering melakukan kekerasan terhadap rakyat untuk kepentingan dirinya sendiri. Barang maupun uang kalau rakyat tidak berikan, dianiaya atau dihukum menjadi budak. Berhubung karena perbuatan-perbuatannya itu, La Ode Afrid dijatuhi hukuman mati dengan jalan diikat dilehernya dan hukuman dilaksanakan di atas pulau Mbela-Mbela kepulauan Tiworo. Demikianlah kemudian ia dikenal dengan nama pengganti "Gogoli Kolono". Pada mulanya pada waktu diputuskan hukuman mati syara kerajaan menentang keputusan yang diambil oleh Muhammad Idrus Kaimuddin dengan alasan bahwa putera Sultan tidak boleh dihukum mati tetapi cukup dikenakan hukuman pengasingan. Atas jawabannya Muhammad Idrus Kaimuddin berkata bahwa hukum tidak mengenal putera sultan. Berkenaan dengan kasus di atas kembali menyimak nasehat Sultan Idrus Kaimuddin terhadap penguasa.

Sehubungan dengan sikap dan tindakan Muhammad Idrus itu, ada tulisan dengan apa yang ditulis oleh Andi Zainal Abidin Farid sebagai berikut: Dalam sejarah Sulawesi Selatan banyak raja-raja dan pembesar yang dibuang, dipecat, dibunuh karena tidak menepati janjinya. Sampai La Pagala nene' Mallomo menjatuhkan hukuman mati kepada anak kandungnya, karena terbukti mencuri kayu peralataan bajak rakyat biasa. Waktu ia ditanya "Muppasinna ke' garo ana'mu aju tabu'e? Ia menjawab: Ade'e temmake Oppo" (hukum tak mengenal anak dan cucu).

\section{Simpulan}

Ajaran-ajaran moral yang mencerah bagi masyarakatnya yang sedang mengalami situasi krisis moral, sebagai akibat dari krisis di masyarakat maupun para penguasa kraton. Pada hakekatnya Sultan Muhammad Idrus Kaimuddin berfungsi sebagai guru masyarakat pada zamannya. Pemikiran atau Ijitihad Sultan Muhammad Idrus Kaimuddin menemukan esensi konsep tata karma atau etika menurut ajaran leluhur dalam Kabanti Bula Malino dan beberapa 
karya Sultan Muhammad Idrus Kaimuddin yang menjadi tuntunan masyarakat dan penguasa kraton di Kesultanan Buton yang pada dasarnya banyak bersumber dari ajaran agama Islam. Pemikiran dalam hal etika, moral, tata krama, maupun nasehat Sultan Kaimuddin memiliki cakrawala pengetahuan dan mendalam pemikiran seorang pemimpin. Besarnya pengaruh agama Islam dalam ajaran beberapa karya Muhammad Idrus Kaimuddin ini membuktikan bahwa berlangsungnya proses akulturasi Islam dan budaya Buton secara berkesinambungan dan mendalam dari masa kerajaan Islam Buton.

Bahwa kelahiran pemikiran berupa ajaran-ajaran moral etika, agama dan kehidupan masyarakat kraton Buton yang berlangsung melalui akulturasi antara Islam dan kebudayaan Buton. Peradaban Buton yang berpusat pada kraton dan ditularkan pada masyarakat Buton secara umum, yang melalui melalui proses dialog kebudayaan antara kebudayaan Buton dengan kebudayaan Islam. Diakui telah terjadi akulturasi antara kebudayaan Buton dengan Islam atau sebaliknya, bahwa telah terjadi pembauran antara budaya Islam dan budaya Buton.

\section{Daftar Pustaka}

Abdurahman, Dudung. 2011. Metodologi Penelitian Sejarah Islam. Yogyakarta: Ombak.

Ambari, Hasan Muarif. 1998. Menemukan Peradaban Jejak Arkeologis dan Historis Islam Indonesia. Jakarta: Logos.

Anonim, 2010. Studi Al Quran Metode dan Konsep. Jogjakarta: Elsaq.

Darmawan, M. Yusran. 2009. Naskah Buton, Naskah Dunia. Bau-Bau: Respect.

Haliadi. 2006. Islam Buton dan Buton Islam (1873-1938). Jogjakarta: KEWANNY.

Kaimuddin, Muhammad Idrus. tt. Kabanti Bula Malino. (Koleksi Pusat Kebudayaan Wolio)

La Niampe, 1998. Kabanti Bula Malino: Kajian Filologis Sastra Wolio Klasik. Bandung: Tesis Program Pascasarjana Unpad.

La Niampe, 2012. Nasehat Muhammad Idrus Kaimuddin Ibnu Badaruddin Al- 
Buthuni. Kendari: Penerbit FKIP Unhalu.

La Niampe, 2012. Undang-Undang Buton Versi Muhammad Idrus Kaimuddin. Kendari: Penerbit FKIP.

La Ode Hazanu, 1984. Buton dalam Sejarah Kebudayaan. Surabaya: Suradipa. Lapidus, Ira M. 1999. Sejarah Sosial Ummat Islam. Jakarta: Rajawali Press.

Ligtvoet A, Beschrijving en Geschiedenis van Boeton. ( BTLV: 1878).

Mubarok, Jaih. 2005. Sejarah Peradaban Islam. Bandung: Pustaka Bani Quraisy.

Muhammad Al Thahan, Mushthafa. 2002. Kemuliaan Sosok Pribadi Muslim. Jakarta: Mustaqim.

Sukri, Sri Suhandjati. 2004. Ijitihad progresif Yasadipura II. Jogjakarta: Gama Media.

Suryanegara, Ahmad Mansur. 2009. Api Sejarah. Bandung: Salamadani.

Susanto Zuhdi, 1999. Labu Rope Labu Wana: Sejarah Butun Abad XVII-XVIII. (Disertasi). Jakarta: Universitas Indonesia.

Yunus, Abdul Rahim. 1995. Posisi Tasawwuf dalam sistem Kekuasaan Kesultanan Buton pada aad XIX. Jakarta: Indonesia-Netherlands Cooperation in Islamic Studies.

Zahari, A.Mulku. 1977. Sejarah dan Adat Fiy Darul Butuni (Buton), Jilid I, II, dan III. Jakarta: Depdikbud.

Zuhdi, Susanto dkk. 1996. Kerajaan Tradisional Sulawesi Tenggara: Kesultanan Buton. Jakarta: Departemen Pendidikan dan Kebudayaan. 